\title{
DE LA INSEGURIDAD GLOBAL A LA MOVILIDAD SELECTIVA
}

\author{
FROM GLOBAL INSECURITY TO THE SELECTIVE MOVILITY
}

*Profesor investigador Universidad de Otava-

lo - Ecuador. Médico y

lo - Ecuador. Médico y
antropólogo. Especiali-

antropólogo. Especiali-

Internacional e Histo-

ria de Religiones en la

Universidad Católica

de Louvain-La-Neuve

Bélgica. Posgrados en

Bélgica. Posgrados en

Nicaragua yMarketing

Nicaragua yMarketing
Mix EENI España. PhD

en Antropología Cogni-

tiva en Atlantic I. Uni-

versity de los Estados

Unidos.cmontufar@

uotavalo.edu.ec

\author{
Por: Carlos E. Montúfar S.*
}

Recibido: 7 de marzo de 2016 - Aprobado: 12 de junio de 2016

\begin{abstract}
RESUMEN
Los movimientos de población han contribuido al desarrollo del conocimiento, a incrementar los intercambios de información y al desarrollo mutuo de sociedades y culturas, que la geografía o las fronteras allende limitaban, no obstante a partir de los atentados del 11 de septiembre de 2001, la percepción de la inseguridad global se convierte en argumento convincente para cerrar las fronteras y limitar la movilidad humana, más aun luego de los atentados de París de noviembre 2015. Desde el surgimiento de lo que se considera como el nuevo paradigma de la inseguridad global, la movilidad humana ha sido representada como factor de riesgo. Este texto por consiguiente propone la necesidad de re-examinar las representaciones habituales de los fenómenos migratorios y sus supuestas relaciones con la inseguridad global.
\end{abstract}

Palabras clave: globalización, inseguridad global, movilidad humana

\begin{abstract}
S
Population movements have contributed to the development of knowledge, to the increase of information exchange and mutual development of societies and cultures, geography or borders, in fact, limited however since the attacks of September 11, 2001 the perception of global insecurity becomes a compelling argument to close the borders and limit human mobility, even more so after the attacks in Paris November 2015. Since the emergence of what is considered as the new paradigm of global insecurity, human mobility has been represented as a risk factor. This text therefore proposes the need to re-examine the usual representations of migratory phenomena and their alleged links with global insecurity.
\end{abstract}

Keywords: Globalization, global insecurity, human mobility.

\section{Introducción}

as sociedades humanas constituyen un misceláneo de culturas con
patrones de vidas muy diversas, con multiplicidad de orígenes,
significaciones y comportamientos que les han permitido ser singulares
en la resolución de sus problemas en la historia. Estas particularidades se
convierten en atributo patrimonial de la especie humana gracias a la amplia
difusión que la tecnología comunicacional facilita. En este contexto, los
movimientos de población han contribuido al desarrollo del conocimiento, 
a incrementar los intercambios de información y al desarrollo mutuo de sociedades y culturas, que la geografía o las fronteras allende limitaban.

La movilidad humana es definida actualmente como el proceso de desplazamiento de la población junto a su cambio de residencia habitual, y se ha perfeccionado en un largo proceso creador desde hace cerca de 70.000 años cuando las bandas de homos sapiens abandonaron su África pretendidamente original, hacia Europa y Asia Oriental (Harari, 2014). A partir del siglo $\mathrm{XV}$ los procesos de colonización europea significaron desplazamientos continuos de población, los cuales se incrementaron en los últimos siglos con el advenimiento de la tecnología de la trasportación. La movilidad es por consiguiente casi tan antigua como la propia historia global del ser humano.

Actualmente, el fenómeno social de la movilidad humana adquiere características masificadoras. Así, tan solo como ejemplo, en 1970, 85 millones de personas fueron objeto de migraciones, aumentando a 175 millones en el año 2000 y 200 millones en el año 2005. Solo en los Estados Unidos, 500.000 personas ingresan cada año, de los cuales del 10 al 15\% ilegalmente ${ }^{1}$.

La realidad social mundial demuestra un incremento sostenido de las poblaciones migrantes, la relación histórica entre población migrante y guerras de invasión añaden una connotación simbólica peyorativa a este término; relacionándolo emocionalmente con inseguridad. Es decir, la oposición a lo conocido como cualidad de ordenamiento, que implica la certeza de normas $\mathrm{y}$, consiguientemente, la previsibilidad de su comportamiento. Un migrante es cómodamente asociado a lo desconocido debido a la ignorancia por parte del sujeto visitante de los códigos de conducta locales. En consecuencia, el adjetivo extranjero es fácilmente asociado a desafuero y peligro como elementos simbólicos, aunque estos imaginarios no sean capaces de confirmar en forma alguna, que su conducta explícitamente provocará incumplimiento y desorden. Herbert Blumer (2015), sostenía que las personas actúan sobre los objetos de su mundo e interactúan con otras personas a partir de los significados que los objetos y las personas tienen para ellas. Es decir, a partir de los símbolos.

Según la Organización Internacional de las Migraciones la movilidad humana es un hecho social vinculado con el ejercicio del derecho humano de la libertad de circulación y se basa en el desplazamiento libre, aunque regulado, que permite a todo ser humano ampliar sus libertades, capacidades y oportunidades de

${ }^{1}$ wwW.migracionoea. org/sicrem i d. o c u mentos sicremi_2011.pdf 
${ }^{2}$ ht t p : / / w w w oimperu.org/oim site/documentos $\mathrm{M}$ o $\mathrm{d}$ u $\mathrm{l}$ o $\mathrm{s}$

Fronteras_Seguras Modulo2.pdf

${ }^{3} \mathrm{http}: / /$ www.politico eu/article/austriasuspends-schengenborder-checks-eumigrants/ mejores condiciones de vida ${ }^{2}$. La movilidad es un concepto reciente, cuya utilidad es integrar en una sola idea a todas las formas de movimiento de personas, como el refugio, la migración internacional, la movilidad forzada por delitos transnacionales (trata de personas), la movilidad en el marco de sistemas de integración, entre otras. A su vez, se reconoce que cada una de estas formas de movilidad está influida por una serie de factores sociales, políticos, culturales, económicos, que no tienen similares características en todos los casos.

Sin embargo, a partir de los atentados del 11 de septiembre de 2001, denominados comúnmente como 9/11, la percepción de la inseguridad global se convierte en argumento convincente para cerrar las fronteras y limitar la movilidad humana, más aun luego de los atentados de París de noviembre 2015.

Desde el surgimiento de lo que se considera como el nuevo paradigma de la inseguridad global, la movilidad humana ha sido representada como factor de riesgo. El miedo, entendido como un sentimiento y una construcción colectiva e individual que trasciende y se modifica según los contextos y las épocas históricas, se ha instaurado en las sociedades modernas como un hecho cultural y social de amplias dimensiones (Mantilla, 2008).

Lo indeseable es lo inseguro, lo que no es fácilmente controlable, manipulable, predecible. El fenómeno migratorio por consiguiente, al no ser sujeto de control total por los Estados, se trastoca en una categoría no previsible por ende deleznable. En este contexto ideológico la tecnología basa su eficiencia en el servicio de la predicción de los fenómenos sociales, siendo los servicios de inteligencia su táctica operativa. La movilidad humana deja de ser percibida como un derecho, transformándose en peligro social inminente, de tal manera que ya en enero 2016, Austria suspendió temporalmente la zona de libre tránsito del acuerdo Schengen en la Comunidad Europea ante la crisis de refugiados ${ }^{3}$.

En consecuencia, la hipótesis argüida en este ensayo propone que la inseguridad global elevada como símbolo y conexa al terrorismo mundial se justifica como argumento de un proceso selectivo de movilidad humana global, a expensas de las amplias multitudes de población, con la excepción de las élites mundiales, afectando el derecho humano; dado que la naturaleza del hombre a lo largo de la historia se definió a expensas de los procesos de movilidad. 


\section{La inseguridad global, símbolo y significado}

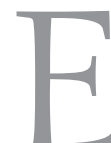

l símbolo permite además de trascender el ámbito del estímulo sensorial y de lo inmediato, ampliar la percepción del entorno, incrementar la capacidad de resolución de problemas y facilitar la imaginación y la fantasía. No obstante, el acto transformado en símbolo también puede adoptar un rol generador de conflictos. En el contexto de este análisis teórico, la inseguridad global como símbolo, es asumida en un rol de una variable cualitativa independiente. Es decir, como fenómeno sobre el que se va a discurrir su capacidad para influir, incidir o perturbar a otras variables.

La particularidad en el análisis surge en el hecho que los significados simbólicos son producto de la interacción social y son ellos los que intervienen en la arquitectura de la conducta humana. Los individuos seleccionan, organizan, reproducen y transforman los significados en los procesos interpretativos en función de sus perspectivas y designios.

En este contexto los fenómenos migratorios en sus procesos de restricción y selección de la movilidad humana son considerados como variables dependientes de la interpretación simbólica de la inseguridad global.

Los fundamentos conceptuales de la terminología utilizada requieren sujeción institucional, puesto que son criterios legales los que categorizan su naturaleza y significado.

La migración humana presenta dos nominaciones: el de la emigración, es decir, desde el punto de vista del lugar o país de donde proviene la población; y el de la inmigración, desde el punto de vista del lugar o país a donde llegan los migrantes. Existe igualmente la definición de migración interna o desplazados internos y externa o internacional, en correspondencia con los límites geográficos y políticos del proceso migratorio. Los desplazados internos son los individuos o grupos de personas que han sido forzados a huir de sus hogares para escapar del conflicto armado, la violencia generalizada, los abusos de los derechos humanos o los desastres naturales o provocados por el ser humano. Tanto los desplazados internos como los refugiados con frecuencia abandonan sus hogares por las mismas razones. Los civiles son reconocidos internacionalmente como refugiados cuando cruzan la frontera nacional en busca de asilo en otro país. Los desplazados internos, mejor conocidos como "IDP", por el acrónimo inglés de "Internally displaced people", permanecen, por cualesquiera razones que sean, en sus propios países ${ }^{4}$. El número de

${ }^{4}$ http://www.acnur. org $/$ t $3 /$ a-quien ayuda/desplazadosinternos/preguntasy-respuestas-sobredesplazados-internos/ 
${ }^{5}$ http://www.acnur. org/t $3 / \mathrm{a}-\mathrm{quien}$ ayuda/desplazadosinternos/

${ }^{6}$ In-migrante, término definido desde el punto de vista del país de acogida. E-migrante desde el punto de vista del país de origen de la persona. Los dos conceptos obedecen a la misma persona en tanto individuo.

${ }^{7}$ ht t p : // blog s worldbank.org voices/es/inmigranteo-refugiado-quesignifica-cadatermino? cid =EXT BoletinES_W_EXT

${ }^{8} \mathrm{~h} t \mathrm{tp}: / \mathrm{W}$ w w oimperu.org/oim site/ documentos/Modulos focumentos/Modulos Modulo2.pdf los desplazados internos alrededor del mundo es alto. Según los datos del Observatorio sobre el Desplazamiento Interno del Consejo Noruego para Refugiados (IDMC-NRC), a finales de 2014 había 38 millones de desplazados internos en todo el mundo 4,7 millones más que en 2013,60\% de los cuales en cinco países afectados por conflictos: Irak, Sudán, República Democrática del Congo (RDC), Siria y Nigeria ${ }^{5}$.

Entre los migrantes externos o internacionales tenemos los migrantes económicos y los refugiados, términos definidos desde la óptica legal. Los inmigrantes ${ }^{6}$ económicos son esencialmente personas que buscan mejores oportunidades económicas, mientras que los refugiados son personas que huyen porque sus vidas corren peligro. La situación específica de estos últimos quedó establecida en la Convención de Ginebra de 1951. En otras palabras, la inmigración económica responde a un "factor de atracción", es decir los inmigrantes se dirigen a un país en el que creen que existe demanda de sus habilidades. Por el contrario, el desplazamiento forzado responde a un "factor de empuje", o sea las personas van al primer lugar posible donde sienten que estarán seguras ${ }^{7}$.

La OIM define el concepto de «movilidad humana» a la movilización de personas de un lugar a otro en ejercicio de su derecho a la libre circulación. Siendo este un proceso complejo y motivado por diversas razones (voluntarias o forzadas), que se realiza con la intencionalidad de permanecer en el lugar de destino por períodos cortos o largos, o, incluso, para desarrollar una movilidad circular. Este proceso implica el cruce de los límites de una división geográfica o política, dentro de un país o hacia el exterior ${ }^{8}$. La movilidad es considerada expresión del ejercicio de un derecho humano. La movilidad es la expresión social del ejercicio del derecho legal a la libre circulación la cual incluye al concepto de migración.

Sin embargo, tanto la inseguridad global como la movilidad humana son conceptos que se representan en tanto objetos en la conciencia. Como tales provocan justificativos y argumentos para las decisiones sociales en lo fáctico. Examinar los contenidos de la conciencia interpretando sus aspectos reales, ideales, o imaginarios, buscando las relaciones esenciales existentes entre las propiedades, objetos, definiciones y fenómenos del concepto migración e inseguridad global es el hilo conductor establecido en este texto. 


\section{Del migrante económico y el refugiado hacia la movilidad como derecho humano fundamental}

I íderes políticos de países de la Organización para la Cooperación y el Desarrollo Económicos (OCDE) han puesto en duda el estatus de los otro país igualmente seguro, pero económicamente más atractivo. Es el caso de los refugiados sirios que abandonan los campamentos en Turquía para dirigirse a la UE. Sin embargo, la causa principal del desplazamiento sigue siendo la misma: la necesidad de huir. Por lo tanto, los refugiados siguen siendo refugiados, incluso si se trasladan. ¿No diríamos eso de una persona judía que escapó de Alemania hacia los Países Bajos en 1937 y luego continuó hacia Argentina en 1939? ${ }^{9}$

Hay una tercera categoría denominada de los "inmigrantes económicos desesperados". Se trata de personas que no están huyendo de la violencia o la persecución y, por lo tanto, no califican como refugiados. Sin embargo, el tipo de riesgos que están dispuestas a asumir y la clase de sufrimientos que están dispuestas a padecer indican que no tienen más opción que migrar a otro país ${ }^{10}$. En esta categoría se encuentran los desesperados habitantes del Sahara que intentan cruzar el Mediterráneo en embarcaciones improvisadas, o los niños de Asia meridional a los que sus padres envían solos a través de Oriente Medio para que puedan tener una oportunidad de llegar finalmente a Europa. Es decir, personas escapando de una violencia estructural o indirecta según Johan Galtung, en la que no existe actor causante, claramente identificado.

No obstante, los seres humanos en movilidad (cambio de residencia habitual) no siempre pueden ser definidos y clasificados desde el estatuto legal de movilidad. Existe el carácter de ilegal del migrante, que produce un fenómeno de pérdida de ciudadanía, generando un segmento de población humana sin derechos fundamentales, casi en esclavitud en los países de acogida. Sin embargo a través de visitas, llamadas telefónicas y el uso de las redes sociales, muchos migrantes llegan a recrear, sostener y (re) descubrir enlaces transnacionales, junto a las redes sociales locales. Usan sus redes transnacionales para aliviar sus necesidades, pero el desarrollo de redes locales todavía aparece como indispensable (Withaeckx, Schrooten, y Geldof,2015). Esta capacidad de "ubicuidad social" puede ser identificada como una nueva destreza del migrante. Obviamente, esta habilidad está condicionada a su condición legal en el país de acogida y a su nivel educativo. Generalmente, cuando estos factores son positivos se convierten en trans-migrantes, es decir

${ }^{9} \mathrm{http}: / / \mathrm{blogs}$. worldbank.org/voices/es

${ }^{10} \mathrm{http}: / / \mathrm{blogs}$. worldbank.org; voices/es/inmigranteo-refugiado-que-
significa-cada-termino 
${ }^{11}$ http://www.oim. org.ec/drupal/es/ migraci\% $3 \% \mathrm{~B} 3 \mathrm{n}-\mathrm{y}-$ desarrollo

${ }^{12}$ Países con baja tasa de natalidad en ciudadanos que mantienen vínculos sociales y movilidad continua entre diversas fronteras.

Finalmente, el concepto de movilidad geográfica (White, 2015) emerge con connotación clara de un derecho humano fundamentado en el artículo 6 de la Carta de los Derechos Humanos que sostiene que todo ser humano tiene derecho, en todas partes, al reconocimiento de su personalidad jurídica. La creación de este complejo concepto obedece al reconocimiento de una nueva era humana sustentada en la globalización del transporte, era del posmodernismo nómada. La Organización Internacional de Migraciones nos previene incluso que en una era de movilidad humana sin precedentes, es particularmente apremiante fomentar una mayor comprensión de los vínculos entre la migración y el desarrollo, y adoptar medidas prácticas para acrecentar los beneficios de la migración de cara al desarrollo; además de elaborar soluciones sostenibles para situaciones migratorias problemáticas ${ }^{11}$.

\section{Discusión}

xisten diversas teorías que intentan explicar causas y consecuencias de 1 la movilidad humana. A nivel macro se incluyen las teorías relacionadas _. con las Disparidades Demográficas y Económicas y la Teoría Sociológica o del Paradigma de la Modernización (De la Dehesa, G. 2008). La primera de ellas se fundamenta en las diferencias entre tasas de natalidad y mortalidad de las sociedades, lo que provoca disparidades entre los países de alta natalidad y los de transición demográfica ${ }^{12}$. La Teoría Sociológica fundamenta la movilidad en aspectos de tipo socio cultural de la modernidad que impulsarían la movilidad o nomadismo internacional como contraste con las sociedades tradicionales de carácter sedentario. El factor económico en relación a la necesidad de mano de obra es también reconocido como causa fundamental del fenómeno migratorio. Finalmente, la dinámica entre migración, pobreza y desarrollo es analizada desde la percepción que son las poblaciones emergentes económicamente quienes pueden generar la posibilidad de migrar.

No obstante, se incluyen los factores intermediarios o meso, donde predominan las redes sociales e instituciones que posibilitan las migraciones (ONG, instituciones intergubernamentales). Incluso, se estudia actualmente las organizaciones criminales como entes promovedoras de migración.

A nivel micro tenemos el Enfoque Económico Neoclásico, la Nueva Teoría Económica de Migración, la Teoría del Mercado Laboral Dual y la de los Sistemas Mundiales. 
La temática de migración y desarrollo reviste gran interés para la comunidad internacional. Este aspecto es uno de los centros estratégicos de la labor de la Organización Internacional de Migraciones (OIM), cuya función en materia de gestión migratoria es capitalizar la relación positiva entre la migración y el desarrollo socioeconómico. La exclusión de los derechos de residencia y ciudadanía de los migrantes económicos es una de las más grandes paradojas de las democracias contemporáneas. Emulando a la historia del Imperio Griego, inventor del imaginario democrático pero restringido como derecho para la mayoría de seres humanos catalogados como esclavos.

La reflexión sobre migración internacional y economía que presume este capítulo podría centrarse en la necesidad de un equilibrio económico entre las diversas regiones. Situación que asumiría un rol disuasivo en las grandes migraciones económicas. Suponiendo que el objetivo social fuere la prevención de este fenómeno de movilidad humana.

Entre los contrasentidos de la globalización se encuentra la amplia movilización de productos frente a la restricción de circulación de seres humanos. Además, la migración internacional conlleva a la mayoría de los países desarrollados del mundo a transformarse en sociedades multiculturales, y aquellas que aún no han alcanzado tal característica, se mueven resueltamente en esta trayectoria. Este aspecto incide en la concepción cultural de las sociedades humanas. Se perfila por consiguiente un mundo intercultural en franca emergencia.

En consideración con la extrema complejidad del fenómeno migratorio internacional, existen diversos enfoques teóricos que aspiran explicarlo. Uno de ellos es el Enfoque Económico Neoclásico (EEN). Según esta visión teórica, la migración se explica en las diferencias de salarios, ese margen entre oferta y demanda de mano de obra que incluye el diferencial en las condiciones laborales interestatales, los costos de la migración, pero suele soslayar el costo del abandono familiar. Como resultado de este desplazamiento la demanda de trabajo decrece y los salarios aumentan en los países pobres, mientras que la demanda de trabajo se incrementa y los salarios caen en los países ricos, conduciendo a un cierto equilibrio. Sin embargo las diferencias salariales internacionales solo reflejan los costes pecuniarios, excluyendo los efectos psíquicos del desplazamiento internacional ${ }^{13}$.

Algunas opiniones, Massey, (1993) diferencian la migración de acuerdo a su nivel de especialización: mano de obra altamente calificada (capital humano)

${ }^{13}$ http: / / www.ugr. es/ r redce/REDCE 10 / articulos/14DouglasD Massey.htm\#uno 
y no calificada (migración). Las migraciones de trabajadores calificados son diferentes al patrón de migración del obrero no calificado. Finalmente, el Estado puede intervenir de manera efectiva solamente regulando su mercado de trabajo.

La Nueva Teoría Económica de la Migración (NTEM) plantea que no son solo las circunstancias laborales que influyen en la migración sino las condiciones de diversidad de los mercados, la decisión familiar, la restricción al acceso de capitales en los países de origen del migrante y los niveles de ingreso familiar. Existen otros enfoques como la del Mercado Laboral Dual (MLD) que propone a las necesidades estructurales de la economía industrial moderna y a las fuerzas operativas económicas como fundamentales en el proceso migratorio, sobre las decisiones de los individuos o de la microeconomía.

Posiblemente, el enfoque más contemporáneo sea el de los Sistemas Mundiales (SM), el cual propone a la misma globalización como causa migratoria; la apertura de los mercados y las necesidades del comercio en ir mucho más allá de los límites nacionales como fundamento de la tendencia migratoria humana (Wallerstein, 2015).

Todos estos enfoques no son contradictorios, más bien conforman un conjunto de teorías convergentes y complementarias que pretenden explicar el fenómeno migratorio, sin embargo, todos ellos tienen como núcleo el paradigma económico. El autor considera que existen factores suplementarios de diversos órdenes como el psicológico, histórico, familiar y/o culturales que influyen, orientan y modulan el flujo de personas en el mundo. La percepción emocional que el emigrante posee del país de acogida gravita en su decisión de destino geográfico; de igual manera la historia familiar de migración modula y dirige su selección; aspectos culturales como la lengua del país de acogida o su proximidad cultural. No obstante, fenómenos tan recientes como las guerras del Medio Oriente (Siria, Irak) producen verdaderos éxodos humanitarios hacia Europa, desequilibrando toda normativa precedente y gravitando sobre la seguridad y la ponderación mundial. Incluso, el terrorismo es considerado "push factor" del fenómeno migratorio (Dreher, 2011).

La globalización estimula en general y profundiza la migración internacional, pero esta ha existido desde tiempos tan remotos como la humanidad misma. Incluso, podría sostenerse que el nomadismo es la condición más natural del ser humano. Si bien, ser nómada no es sinónimo de migrante, existe un 
cierto paralelo en su naturaleza: la búsqueda de un lugar más propicio a la vida humana. Además el sedentarismo es paradójico en relación al hábitat humano. Si bien las migraciones son evidenciadas como problema global, el fenómeno inverso al nomadismo migracional, es decir, el sedentarismo urbano genera inmensos desafíos. Según ONU-Hábitat las ciudades se enfrentan a retos demográficos, ambientales, económicos, sociales y espaciales sin precedentes. Ha habido un cambio fenomenal hacia la urbanización, con 6 de cada 10 personas en el mundo residiendo en zonas urbanas en 2030. Más del 90 por ciento de este crecimiento tendrá lugar en África, Asia, América Latina y el Caribe ${ }^{14}$.

La Teoría de la Dependencia sostenida por importantes intelectuales como André Gunder Frank, Raúl Prebish, Celso Furtado, Theotomio dos Santos, Samir Amín, Enzo Faleto, Ruy Mauro Marini y Henrique Cardoso, proclamaba que las naciones pobres del sur proveen a las naciones ricas de sus recursos naturales, su mano de obra barata y un destino ideal para la tecnología obsoleta, situaciones sin las cuales estas últimas naciones no podrían mantener el nivel de vida al que están acostumbrados (Prebisch, 1982). Por consiguiente, en las inequidades se encuentra el sustento explicativo básico del fenómeno migratorio.

Sin embargo, a partir de los atentados terroristas del 2001 el fenómeno migratorio es percibido desde la nueva óptica de la inseguridad. Reforzados por los atentados de París en 2015, y la ola de migración procedente de la guerra en Medio Oriente, las políticas que facilitan las migraciones son percibidas como factor de riesgo y el migrante, como objeto generador de peligro.Un nuevo marco interpretativo simbólico comienza a ser asumido tanto a nivel institucional como en la ciudadanía de los países principalmente afectados. El derecho a la movilidad humana es transpuesto a factor de riesgo.

Maximiliano Korstanje (2015) sostiene que el arquetipo de un mundo inestable ayuda a legitimar guerras preventivas que permitirían a las potencias como los Estados Unidos intervenir en naciones autónomas, pero sospechosas. Colombia fue el pretexto para mostrar cuán peligrosa es la migración y el narcotráfico para los estados occidentales. Korstanje y Skol (2013) llegan incluso a sostener que el terrorismo es un resultado de la producción del sistema de organización del trabajo del régimen capitalista.

¿A quién beneficia esta vinculación epistémica entre migración e inseguridad global?

${ }^{14}$ http://unhabitat. org/un-habitat-at-aglance) 
${ }^{15}$ La autora cita que de acuerdo a la investigación del 2010 del Wahington Post, estas instituciones creadas contra el terrorismo incluyen: the Departement The Decurity, Homeland Security, The National Counterterrorism Center y TheTransportation Security Administration.

h t t p s : / / w w w .

foreignaffairs.com/

articles/middle-east/ isis-not-terroristg roup ? cid = nlc twofa-20151230\&sp mid $=50372351 \&$ sp r $\mathrm{d}=\mathrm{Y} 2 \mathrm{FybW}$ 9udDUzOH lhaG9vLmVzSO\&spM ilingID $=503723518$ sp Use Usen - MOEZN J (4) 840078528\&spReport $\mathrm{d}=$ ODQwMDc4NTI4SO
Desde la dinámica de la globalización de mercancías y de la cultura global de consumo, el flujo humano aparece como un fenómeno innecesario, incluso no apetecible al sistema. Esto no excluye que al criminalizar al migrante, sustrayéndole su categoría de ciudadano por el de ilegal, se apertura una extensa gama de posibilidades de explotación social a su coste.

\section{Conclusión}

l fenómeno de la inseguridad global da la impresión de estar alineado $\checkmark$ con el ingenio argumentativo de los círculos de poder mundial para L extender y consolidar un tipo de globalización seguritaria u doctrina de la seguridad nacional, arrogándose el derecho de intervención en caso de riesgos potenciales (Chávez, 2008), justificando incluso el adoptar medidas excepcionales en las legislaciones antiterroristas para mantener la seguridad nacional como en el caso del Reino Unido (Ahmed, 2015) o la creación y/o reorganización de 263 instituciones ${ }^{15}$ gubernamentales de los Estados Unidos, en respuesta al terrorismo desde el 11/9 (Cronin, 2015).

Los círculos de poder estarían adjudicándose jurisdicción moral de intervención desde lo mundial hacia todo lo local, inhibiendo la movilidad humana y provocando un fenómeno de asimilación entre los conceptos de inseguridad y terrorismo, a pesar de que los estatutos migratorios de los perpetradores de atentados suelen cumplir los procedimientos legales internacionales (Cronin, 2013).

Este texto por consiguiente propone la necesidad de re-examinar las representaciones habituales de los fenómenos migratorios y sus supuestas relaciones con la inseguridad global.

\section{BIBLIOGRAFÍA}

Ahmed, S. (2015). The 'emotionalization of the "war on terror"': Counter-terrorism, fear, risk, insecurity and helplessness. Criminology \& Criminal Justice: An International Journal, 15(5), 545560. doi:10.1177/1748895815572161

Blumer, H. (1986). Symbolic interactionism: perspective and method. University of California Press.

Chávez, N. (2008). Cuando los mundos convergen: terrorismo, narcotráfico y migración post 9/11. Flacso-Sede Ecuador.

Cronin, A. K. (2013). Why drones fail. Foreign Affairs, 92(4), 44-54. 
De la Dehesa, G. (2008). Comprender la inmigración. Alianza Editorial.

Dreher, A.; Krieger, T. \& Meierrieks, D. (2011). Hit and (they will) run: The impact of terrorism on migration. Economics Letters, 113(1), 42-46. doi:10.1016/j.econlet.2011.05.044

Harari, Y. N. (2014). De animales a dioses (Sapiens): Una breve historia de la humanidad. Debate.

Korstanje, M. E. (2015). Review of «Cuando los mundos convergen, terrorismo, narcotráfico y migración post 9/11 [WhentheWorlds Converge: Terrorism, Narco-traffic and Migration post 9/11]». Essays in Philosophy, 16(1), 8.

Korstanje, M. E. \& Skoll, G. (2013). “Discussing concepts: terrorism and tourism in the spotlight.” Turismo y Desarrollo: Revista de Investigación en Turismo y Desarrollo Local, 6(14).

Malik, K. (2015). The failure of multiculturalism. Foreign Affairs, 94(2), 21-32.

Mantilla-Valbuena, S. C. (2008). Más allá del discurso hegemónico: narcotráfico, terrorismo y narcoterrorismo en la era del miedo y la inseguridad global. Papel Político, 13(1), 227-259.

Massey, Douglas S., et al. (1993). Theories of international migration: a review and appraisal. Population and development review: 431-466.

Prebisch, Raúl. (1982). Capitalismo periférico. Crisis y transformación.

Valles, M. S. (2000). Técnicas cualitativas de investigación social. Síntesis Editorial.White, M. J. (Ed.). (2015). International Handbook of Migration and Population Distribution (Vol. 6). Springer.

Wallerstein, I. (2015). Free flows and real obstacles. Mass migration in the world-system: Past, present, and future.

Withaeckx, Sophie, MiekeSchrooten, and Dirk Geldof. (2015). Living across borders: The everyday experiences of moroccan and brazilian transmigrants in Belgium. Crossings: Journal of Migration \& Culture 6.1 (2015): 23-40. SocINDEX with Full Text.Web. 17 Mar. 2015. 